\title{
Association Between Gastrointestinal Stromal Tumors and Other Malignancies: It Is Only a Matter of Time ? A Case Series and an Overview of Systematic Reviews
}

\author{
Mauro Podda $^{1}$ (D) $\cdot$ Giulia Ferraro $^{1} \cdot$ Salomone Di Saverio ${ }^{2} \cdot$ Alessandro Cois $^{1} \cdot$ Oreste Nardello $^{1} \cdot$ Gaetano Poillucci $^{3}$. \\ Marco Vito Marino ${ }^{4}$. Adolfo Pisanu ${ }^{1}$
}

(C) Springer Science+Business Media, LLC, part of Springer Nature 2019

\begin{abstract}
Purpose Little is known about the sporadic coincidence of gastrointestinal stromal tumors (GISTs) with second primary tumors (SPTs). The aim of this study is to clarify if there is a clinicopathologic correlation responsible for the synchronous or metachronous occurrence of SPTs in GIST patients.

Methods We carried out a single-center, retrospective analysis on patients with GISTs surgically treated at our institution from January 2019 to June 2019. Two groups of patients were identified: isolated GIST (group A) and GIST associated with SPT (group B). A meta-review was conducted with the aim to examine the published systematic reviews that included studies assessing the SPT risk in GIST patients.

Results Thirty-nine patients were surgically treated for GIST during the study period, with seven (17.9\%) of them having other SPTs. SPTs were most frequent in the colon. Group A patients had a lower mean age at initial diagnosis $(56.8 \pm 15.2$ vs. $73.4 \pm$ $16.6, P=0.012)$. No statistically significant difference was found between the two groups in terms of tumor location, mitotic index, Ki-67 expression, risk classification, and imatinib therapy. The overview showed that the cumulative prevalence rate of SPTs ranged from 9.3 to $18.0 \%$. SPTs were more frequent in the gastrointestinal tract (37.9-95.0\%), followed by the genitourinary tract.

Conclusion GIST patients under our care experienced a 17.9\% overall risk of developing SPTs with different histology. When comparing patients with isolated GIST and patients with GIST and SPT, age was the only variable significantly related to the development of other neoplasms. However, the potential non-random association and causal relationship between GISTs and SPTs remain to be investigated.
\end{abstract}

Keywords Gastrointestinal stromal tumors · Associated neoplasms $\cdot$ Synchronous malignancies $\cdot$ Secondary primary tumors Overview of systematic reviews

Mauro Podda

mauropodda@ymail.com

1 Department of Surgery, Cagliari University Hospital "D. Casula", University of Cagliari, SS 554, Km 4,500, 09042 Cagliari, Monserrato, Italy

2 Department of Surgery, Cambridge Colorectal Unit, Addenbrooke's Hospital NHS Foundation Trust, University of Cambridge, Cambridge, UK

3 Department of Surgery "Paride Stefanini", Policlinico Universitario Umberto I, Sapienza University, Rome, Italy

4 Department of General Surgery, Hospital Universitario Marques de Valdecilla, Santander, Cantabria, Spain

\section{Introduction}

Although they are rare, gastrointestinal stromal tumors (GIST) are the most frequent forms of mesenchymal subepithelial neoplasia affecting the gastrointestinal tract.

GISTs represent about $0.1-1 \%$ of all malignant neoplasms of the gastrointestinal tract and have an average annual incidence of 11-19 cases per million [1,2].

A recent meta-analysis conducted on 13,550 patients from different countries, showed that the global incidence of GISTs is $10-15$ cases per million per year, with a lower incidence recorded in Shanxi province in China (4.3 cases per million per year), and a higher incidence in Hong Kong, Shanghai, 
Taiwan, and northern Norway (19-22 cases per million per year) [3].

Almost $25 \%$ of reported GISTs represent incidental findings during diagnostic or therapeutic procedures for other benign or malignant diseases or during the follow-up for a previously known tumor $[4,5]$.

The majority of GISTs are diagnosed as single lesions in patients between 50 and 60 years of age, with a slight predominance of males [5-7]. They occur most commonly in the stomach $(60-70 \%)$, followed by the small intestine $(20-30 \%)$, duodenum (4-5\%), rectum $(4-5 \%)$, colon $(<2 \%)$, and esophagus $(<1 \%)$. Extremely rare are tumor localizations on the omentum, mesentery, and retroperitoneum [4, 8, 9].

Conversely, about $5 \%$ of cases are reported in association with other second primary tumors (SPTs) occurring in familial syndromes, such as the Primary Familial Gist Syndrome, Neurofibromatosis type 1 (NF-1), and Carney's triad [10].

Outside of these syndromic forms, little is known about the sporadic coexistence of GISTs with SPTs, although multiple single institution and population-based studies have reported GIST patients to have an increased risk of presenting with additional malignancies, either synchronously or during follow-up [7, 11-14].

GIST patients have a twofold risk of being diagnosed with a SPT than the general population, and patients with a second tumor have a worse survival rate than those with an isolated GIST [15, 16].

The reported incidence rate of GISTs associated with other tumors has a broad range (4.5-33\%), and the type and site of associated tumor may vary considerably between series $[7,17$, 18].

The frequency of these associations and the spectrum of malignancies involved have been mainly described in the literature in form of case reports and case series, insufficient to prove if gene mutations or the effect of common carcinogenic pathways on adjacent tissues may be possible explanations for the onset of SPTs [7, 14].

The aim of this study was to report on a case series of patients with GIST and other associated epithelial and stromal neoplasms to clarify if there was a clinicopathologic correlation responsible for the synchronous or metachronous occurrence of these tumors, or if this phenomenon is absolutely random.

Among the various parameters considered (sex, age, presentation, location, volume, histotype, immunophenotype, mitotic activity, and mutational structure) those potentially playing a significant role in the onset of SPTs in GIST patients were investigated in an attempt to identify any risk factor for this association. Moreover, we carried out an overview of the published systematic reviews from the literature to provide a descriptive assessment of the association between SPTs and GISTs.

\section{Materials and Methods}

\section{Study Design}

After obtaining institutional review board approval, we carried out a single-center, retrospective observational analysis on patients with GISTs. Upon reviewing all cases, we searched for the patients with GIST and diagnosed with SPTs, either synchronic or metachronic. Synchronous occurrence was considered if a patient was diagnosed with GIST and SPT within a 6-month period. Metachronous occurrence was considered SPT being diagnosed greater than 6 months after GIST.

We analyzed the possible relationship among pathological and clinical characteristics of the GIST and the occurrence of SPT. After obtaining from patients written consent to access personal data for research purpose, the clinical charts of all consecutive patients with a diagnosis of GIST referred to our institution (Department of General, Emergency and Minimally Invasive Surgery of the Cagliari University Hospital, Italy) between January 2010 and June 2019 were retrospectively reviewed.

The diagnosis of GIST was carried out based on compatible histology along with the positivity to c-Kit. Those with negative c-Kit but positivity for other immunohistochemistry markers such as DOG-1, CD34, Desmin, AML, and S100 were also included.

NF-1, familial GIST syndromes, Carney's triad, nonmelanoma skin cancer, and benign tumors were excluded.

The series of patients was divided into two groups: isolated GIST (group A) and GIST associated with SPT (group B). Group A patients were further classified into four subgroups, in accordance with the classification proposed by Fernandez et al. [11]: type 1s (diagnosis of GIST first and synchronous associated neoplasm during GIST staging or intraoperative finding), type $1 \mathrm{~m}$ (diagnosis of GIST first and metachronous associated neoplasm, diagnosed during GIST follow-up), type $2 \mathrm{~s}$ (synchronous incidental GIST diagnosed during the staging of associated tumor or intraoperatively), and type $2 \mathrm{~m}$ (metachronous GIST diagnosed during associated tumor follow-up). Follow-up was obtained either in outpatient clinic or by mean of telephone calls.

\section{Variables}

Patient demographic characteristics (age at diagnosis and gender), clinical presentation, imaging investigations, and therapeutic strategies were reviewed. Tumor characteristics of patients with GIST were also reviewed, with particular reference to tumor size and location, mitotic index, Ki-67 expression, histology, immunohistochemistry, risk group, surgical margin status, and characteristics of the SPT. Surgical margin status of GIST was classified into three categories: R0 (complete gross 
and microscopic resection), R1 (microscopic residual lesions), and $\mathrm{R} 2$ resections (retention of any gross residual tumor) [19]. Risk groups were assessed according to the Armed Forces Institute of Pathology (AFIP) criteria by Miettinen et al. [20].

\section{Statistical Analysis}

The differences between groups were analyzed applying the Fisher's exact test for qualitative data and the average comparison by Student's $t$ test for the quantitative ones. Data were expressed as mean \pm standard deviation or absolute numbers and percentage, where appropriate.

All statistical analyses were conducted using the Statistical Package for Social Sciences-IBM SPSS v23.0 (SPSS, Inc., Chicago, IL). We considered results to be statistically significant at a two-sided $P$ value of $<0.05$.

The present study was approved by the Institutional Review Board and Ethics Committee of the "Policlinico Universitario di Monserrato," Cagliari University Hospital.

\section{Overview of Systematic Reviews}

We conducted a meta-review with the aim to examine the published systematic reviews that included studies assessing the SPT risk in GIST patients and to analyze clinicopathologic variables that possibly link GISTs to secondary tumors.

Only reviews that satisfied the following criteria were included: to have used a systematic review method (critical reviews, literature reviews, meta-analyses); to have indicated the method for identifying and evaluating studies for inclusion; and to have included studies that investigated the incidence of SPTs (either synchronic and metachronic) in patients with GIST.

The following electronic databases were searched: PubMed, EMBASE, SCOPUS, Web of Science, and the Cochrane Library. Boolean searches were conducted to systematically link the various combinations of search terms (Gastrointestinal Stromal Tumors, Gastrointestinal Stromal Neoplasms, GIST, GISTs, Other Malignancies, Second Primary Malignancies, Second Primary Neoplasms, Second Primary Cancer, Synchronous, Metachronous, Coexistence, Review).

Reference lists of relevant studies were searched manually, and the "related articles" function in PubMed was used to identify additional potential systematic reviews. The search was performed for records published through August 2019. No language restrictions were applied.

The R-AMSTAR checklist was used to quantitatively measure the methodological quality of included systematic reviews [21]. A total score of 22 was required for systematic review inclusion in the meta-review.

All stages of study identification, selection, methodological quality assessment and data extraction were carried out independently by two reviewers (M.P. and A.P.). Inconsistencies were resolved through discussion until a consensus was reached, or based on the assessment by a third reviewer who was involved in the discussion (S.D.S.).

\section{Results}

\section{Baseline Characteristics of Patients with GIST}

From January 2010 to June 2019, a total of 39 patients were surgically treated for GIST at our institution, with seven (17.9\%) of them having other SPT associated.

Baseline characteristics for all patients with GIST are summarized in Table 1.

The entire study population included 25 males (64.1\%) and 14 females $(35.9 \%)$, with a mean age at initial diagnosis of $58.6 \pm 17.3$ years.

Fourteen patients $(35.9 \%)$ were asymptomatic at the time of diagnosis, and GIST was an incidental finding during imaging investigations carried out for other medical reasons. Out of 25 symptomatic patients, the most frequent symptom was gastrointestinal bleeding in nine cases $(23.2 \%)$, followed by abdominal pain in 7 cases (17.9\%), anemia in 4 cases (10.3\%), dyspepsia in 2 cases $(5.1 \%)$, intestinal obstruction in 2 cases (5.1\%), and hemorrhagic shock in 1 case $(2.5 \%)$.

All patients' tumors were surgically removed, and three (7.7\%) were successfully approached laparoscopically. Thirteen patients underwent gastric wedge resection (33.5\%), ten patients underwent small bowel resection (25.6\%), six subtotal gastrectomy (15.5\%), five total gastrectomy $(12.9 \%)$, one total gastrectomy plus left hepatectomy (2.5\%), one total gastrectomy plus splenectomy $(2.5 \%)$, one gastric wedge resection plus small bowel resection (2.5\%), one small bowel resection plus hysteroannessiectomy (2.5\%), and one local rectal excision $(2.5 \%)$.

Four operations were performed in emergency settings, two for hemoperitoneum and two for intestinal obstruction.

Four patients $(10.2 \%)$ received preoperative imatinib therapy ( $400 \mathrm{mg}$ /daily; mean duration 8 months) in order to downsize the tumor and avoid multiorgan resections and intraoperative GIST capsule rupture. Adjuvant imatinib therapy was administered to 12 high-intermediate risk GIST patients $(30.7 \%)$. Liver metastases were found intraoperatively in one patient with huge gastric GIST invading the left hepatic lobe and requiring a total gastrectomy plus left hepatectomy.

After a mean follow-up time of $101 \pm 44.1$ months, 35 patients $(89.7 \%)$ were alive without evidence of GIST recurrence. Four patients $(10.2 \%)$ developed metastases from GIST: one patient was diagnosed with peritoneal single metastasis located in the mesentery of the small intestine 2 years after a gastric wedge resection for a GIST localized in the greater curvature of the stomach. A resection of the peritoneal 
Table 1 Baseline characteristics of patients with GIST

\begin{tabular}{|c|c|}
\hline No. of patients & 39 \\
\hline Age $($ mean $\pm \mathrm{SD})$ & $58.6 \pm 17.3$ \\
\hline Gender (M:F) & $25: 14$ \\
\hline \multicolumn{2}{|l|}{ Clinical presentation $(N(\%))$} \\
\hline Asymptomatic & $14(35.9)$ \\
\hline Gastrointestinal bleeding & $9(23.2)$ \\
\hline Abdominal pain & $7(17.9)$ \\
\hline Anemia & $4(10.3)$ \\
\hline Dyspepsia & $2(5.1)$ \\
\hline Intestinal obstruction & $2(5.1)$ \\
\hline Hemorrhagic shock & $1(2.5)$ \\
\hline \multicolumn{2}{|l|}{ Imaging $(N(\%))$} \\
\hline CT scan & $39(100)$ \\
\hline MRI scan & $2(5.1)$ \\
\hline Gastrointestinal endoscopy & $28(71.8)$ \\
\hline EUS & $25(64.1)$ \\
\hline \multicolumn{2}{|l|}{ Surgical intervention $(N(\%))$} \\
\hline Gastric wedge resection & $13(33.5)$ \\
\hline Small bowel resection & $10(25.6)$ \\
\hline Subtotal gastrectomy & $6(15.5)$ \\
\hline Total gastrectomy & $5(12.9)$ \\
\hline Total gastrectomy + left hepatectomy & $1(2.5)$ \\
\hline Total gastrectomy + splenectomy & $1(2.5)$ \\
\hline Gastric wedge resection + small bowel resection & $1(2.5)$ \\
\hline Small bowel resection + hysteroannessiectomy & $1(2.5)$ \\
\hline Local rectal excision & $1(2.5)$ \\
\hline \multicolumn{2}{|l|}{ Emergency operation $(N(\%))$} \\
\hline Hemoperitoneum & $2(5.1)$ \\
\hline Intestinal obstruction & $2(5.1)$ \\
\hline Preoperative imatinib therapy $(N(\%))$ & $4(10.2)$ \\
\hline Adjuvant imatinib therapy $(N(\%))$ & $12(30.7)$ \\
\hline Metastasis at surgery $(N(\%))$ & $1(2.5)$ \\
\hline Metastasis at follow-up $(N(\%))$ & $4(10.2)$ \\
\hline Follow-up (mean $\pm \mathrm{SD}$; months) & $101 \pm 44.1$ \\
\hline
\end{tabular}

$C T$, computed tomography; MRI, magnetic resonance imaging; EUS, endoscopic ultrasound

metastasis was carried out and the final pathology showed R0 margins status. One patient was diagnosed with multiple liver metastases from GIST after 4 years from the primary gastric resection and treated with imatinib. One AFIP-Miettinen high risk patient was diagnosed with lymphatic metastases at the celiac trunk after 5 years from the total gastrectomy. This patient, who developed adverse reaction to imatinib and had to stop the adjuvant therapy, underwent lymphadenectomy of the celiac trunk six years after the primary resection. A last patient, who underwent total gastrectomy and splenectomy for a GIST of the gastric fundus, was diagnosed with a metastasis at the frontal bone, which was fully resected by the neurosurgeon.

\section{Tumor Characteristics of Patients with GIST}

Tumor characteristics of patients with GIST are showed in Table 2. The most frequent location of GIST was the stomach in 25 cases $(64.2 \%)$, followed by the jejunum/ileum in 11 cases

Table 2 Tumor characteristics of patients with GIST

\begin{tabular}{|c|c|}
\hline Tumor size (mean $\pm \mathrm{SD}$; cm) & $14.1 \pm 8.3$ \\
\hline \multicolumn{2}{|l|}{ Tumor location $(N(\%))$} \\
\hline Stomach & $25(64.2)$ \\
\hline Small intestine & $11(28.3)$ \\
\hline Stomach + small intestine & $1(2.5)$ \\
\hline Colon & $1(2.5)$ \\
\hline Rectum & $1(2.5)$ \\
\hline \multicolumn{2}{|l|}{ Mitotic index (50 HPF; $N(\%))$} \\
\hline$<10$ & $34(87.2)$ \\
\hline$\geq 10$ & $5(12.8)$ \\
\hline \multicolumn{2}{|l|}{$\mathrm{Ki}-67(\% ; N(\%))$} \\
\hline$<5$ & $23(58.9)$ \\
\hline $5-10$ & $11(28.3)$ \\
\hline$>10$ & $5(12.8)$ \\
\hline \multicolumn{2}{|l|}{ Histology $(N(\%))$} \\
\hline Fusiform & $22(56.4)$ \\
\hline Mixed morphology & $7(17.9)$ \\
\hline Epithelioid & $10(25.6)$ \\
\hline \multicolumn{2}{|l|}{ AFIP-Mettienen risk category $(N(\%))$} \\
\hline High & $10(25.6)$ \\
\hline Intermediate & $3(7.8)$ \\
\hline Low & $10(25.6)$ \\
\hline Very low & $16(41.0)$ \\
\hline \multicolumn{2}{|l|}{$\operatorname{ICC}(N(\%))$} \\
\hline CD117 & $31(79.5)$ \\
\hline CD34 & $22(56.4)$ \\
\hline Desmin & $4(10.2)$ \\
\hline DOG1 & $37(94.8)$ \\
\hline AML & $9(23.1)$ \\
\hline S100 & $12(30.7)$ \\
\hline \multicolumn{2}{|l|}{ Surgical margin status $(N(\%))$} \\
\hline $\mathrm{R} 0$ & $36(92.3)$ \\
\hline $\mathrm{R} 1$ & $3(7.7)$ \\
\hline \multicolumn{2}{|l|}{ Associated malignancies $(N(\%))^{\mathrm{a}}$} \\
\hline Synchronous (type $1 \mathrm{~s}=1$; type $2 \mathrm{~s}=2$ ) & $3(7.7)$ \\
\hline Metachronous (type $1 \mathrm{~m}=1 ;$ type $2 \mathrm{~m}=3$ ) & $4(10.2)$ \\
\hline Colorectal adenocarcinoma & $2(29.0)$ \\
\hline Laringeal adenocarcinoma & $1(14.2)$ \\
\hline Liposarcoma & $1(14.2)$ \\
\hline Endometrial adenocarcinoma & $1(14.2)$ \\
\hline Prostatic adenocarcinoma & $1(14.2)$ \\
\hline Osteosarcoma & $1(14.2)$ \\
\hline
\end{tabular}

${ }^{\mathrm{a}}$ In accordance with the classification proposed by Fernández et al. [22] 
(28.3\%), stomach and small intestine in 1 case $(2.5 \%)$, and colon in 1 case $(2.5 \%)$. The mean size of GIST was $14.1 \pm 8.3 \mathrm{~cm}$, with a mitotic index $<10(50 \mathrm{HPF})$ in 34 patients $(87.2 \%)$ and $\geq 10$ in 5 patients $(12.8 \%)$. Ki-67 expression was $<5 \%$ in 23 cases $(58.9 \%)$, between 5 and $10 \%$ in 11 cases $(28.3 \%)$, and $>10 \%$ in 5 cases $(12.8 \%)$. Pathologically, the most frequent histotype was the fusiform type in 22 patients $(56.4 \%)$, followed by the epithelioid type in 10 patients $(25.6 \%)$, and the mixed morphology type in 7 patients (17.9\%).

According to the AFIP-Miettinen risk stratification system, 10 cases $(25.6 \%)$ were classified as high risk, 3 cases $(7.8 \%)$ as intermediate risk, 10 cases $(25.6 \%)$ as low risk, and 16 cases $(41.0 \%)$ as very low risk of progressive disease.

Thirty-one cases of GIST were CD117 positive (79.5\%). Twenty-two cases of GIST showed positivity for CD34 (56.4\%), four cases were Desmin-positive (10.2\%), thirty-seven cases were DOG1-positive (94.8\%), nine cases showed AML positivity (23.1\%), and twelve cases S100 positivity (30.7\%).

After surgical resection, thirty-six patients $(92.3 \%)$ had R0 surgical resection margins, whereas three patients had R1 resection $(7.7 \%)$.

The subgroup of GIST patients with other SPTs was composed of seven patients $(17.9 \%)$. Mean age at diagnosis was $73.4 \pm 16.6$ years. In four patients $(57.1 \%)$, GISTs were located in the stomach, in two cases $(28.6 \%)$, in the ileum, and in one case $(14.3 \%)$, two GISTs were diagnosed in the same patients in the stomach and small intestine (Table 3). Mean GIST size in this subgroup of patients was $16.3 \pm 8.7 \mathrm{~cm}$. Mitotic index was $<10(50 \mathrm{HPF})$ in five cases $(71.4 \%)$ and $\geq 10$ (50 HPF) in two cases $(28.6 \%)$. Histology was fusiform cell in three cases $(42.8 \%)$, epithelioid in two cases $(28.5 \%)$, and mixed morphology in two cases $(28.5 \%)$. According to the risk categories, one patient $(14.3 \%)$ had high risk, one patient intermediate risk, two patients $(28.6 \%)$ had low risk, and three patients $(42.8 \%)$ had very low risk.

$\mathrm{R} 0$ resection was achieved in all procedures for the treatment of the GISTs, and no patient received additional imatinib at any moment during treatment.

SPTs were most frequent in the colon. Furthermore, one laringeal adenocarcinoma, one liposarcoma, one endometrial adenocarcinoma, one prostatic adenocarcinoma, and one osteosarcoma were diagnosed in this subgroup of patients. More specifically, three patients $(7.7 \%)$ were diagnosed with synchronous SPT (one type $1 \mathrm{~s}$ and two type $2 \mathrm{~s}$ according to the classification proposed by Fernández et al.) and four patients (10.2\%) had a metachronous SPT (one type $1 \mathrm{~m}$ and three type $2 \mathrm{~m}$ ).

\section{Demographic and Clinicopathologic Data Comparison Between Group A (Isolated GIST) and Group B (GIST with SPTs)}

When comparing isolated GIST patients (group A) and GIST with SPT patients (group B), group A patients had a lower mean age at initial diagnosis $(56.8 \pm 15.2$ vs. $73.4 \pm 16.6, P=$ 0.012).

Conversely, as reported in Table 3, no statistically significant difference was noted between the two groups in terms of gender, tumor location, mitotic index, Ki-67 expression, histology, AFIP-Miettienen risk classification, preoperative and adjuvant imatinib therapy, and surgical margin status.

\section{Overview of Systematic Reviews on GIST Associated with SPTs}

A flowchart showing the process of selection for the included systematic reviews is presented in Fig. 1.

Searches of electronic databases and reference lists of relevant studies identified 247 reports. After exclusion of abstracts, duplicate references, non-relevant literature, and manuscripts not satisfying the inclusion criteria, a total of five systematic reviews were finally included [7, 17, 23-25].

Table 4 provides a summary of the characteristics and main findings of each included systematic review.

Overall, two systematic reviews analyzed epidemiological and clinicopathologic behaviors of synchronous SPTs in patients diagnosed with GIST [17, 24], whereas three systematic reviews assessed results for both synchronous and metachronous SPTs [7, 23, 25], with the number of included studies ranging from 6 to 32, and patients' number ranging from 445 to 18,170 .

The R-AMSTAR scores of the five included reviews ranged from 22 to 36 , with a mean of $25.6 \pm 5.2$.

The cumulative prevalence rate of SPTs ranged from $9.3 \%$ in the study by Agaimy et al. to $18.0 \%$ in the study by Diamantis et al. The main anatomic sites of origin of GISTs with SPTs were the gastroesophageal tract (62.7-67.2\%), followed by the small bowel (19.8-28.1\%) and the colorectal tract $(2.8-3.6 \%)$.

GISTs with SPTs showed a mean size ranging from $3.9 \pm$ $0.7 \mathrm{~cm}$ in the study by Giuliani et al. to $17.8 \pm 8.1 \mathrm{~cm}$ in the study by Diamantis et al. Mean age at initial diagnosis varied from $63.2 \pm 3.6$ years in the study by Petrelli et al. to 77 years in the study by Núnez Martín et al., with no relevant difference between studies that investigated synchronous and metachronous SPTs and those focused only on synchronous associated tumors.

The risk category assessment for patients with GIST and SPT according to the classification proposed by Miettinen et al. [20], showed similar distributions compared with those of GISTs patients without SPTs, being the majority of GISTs classified as low/very low risk (48.1-85.1\%). According to the results of our overview, SPTs were far more frequent in the gastrointestinal tract $(37.9-95.0 \%)$, followed by the genitourinary tract $(2.5-22.4 \%)$ and breast (4.6-9.2\%). SPTs were represented by leukemias and lymphomas in a proportion of patients ranging from 1.0 to $8.1 \%$. The category "other," 
Table 3 Demographic and clinicopathologic data comparison between the two groups

\begin{tabular}{|c|c|c|c|}
\hline & Group A (isolated GIST) & Group B (GIST + other malignancies) & $P$ value \\
\hline No. of patients & 32 & 7 & \\
\hline Age $($ mean $\pm \mathrm{SD})$ & $56.8 \pm 15.2$ & $73.4 \pm 16.6$ & 0.012 \\
\hline Gender (M:F) & $22: 10$ & $5: 2$ & 1.000 \\
\hline Tumor size $($ mean $\pm \mathrm{SD} ; \mathrm{cm})$ & $12.1 \pm 7.9$ & $16.3 \pm 8.7$ & 0.218 \\
\hline \multicolumn{4}{|l|}{ Tumor location $(N(\%))$} \\
\hline Stomach & $21(65.6)$ & $4(57.1)$ & 0.659 \\
\hline Small intestine & $9(28.2)$ & $2(28.6)$ & 1.000 \\
\hline Stomach + small intestine & - & $1(14.3)$ & \\
\hline Colon & $1(3.1)$ & - & \\
\hline Rectum & $1(3.1)$ & - & \\
\hline \multicolumn{4}{|l|}{ Mitotic index (50 HPF; $N(\%))$} \\
\hline$<10$ & $29(90.6)$ & $5(71.4)$ & 0.213 \\
\hline$\geq 10$ & $3(9.4)$ & $2(28.6)$ & \\
\hline \multicolumn{4}{|l|}{$\mathrm{Ki}-67(\% ; N(\%))$} \\
\hline$<5$ & $21(65.6)$ & $2(28.6)$ & 0.100 \\
\hline $5-10$ & $8(25.1)$ & $3(42.8)$ & 0.379 \\
\hline$>10$ & $3(9.3)$ & $2(28.6)$ & 0.213 \\
\hline \multicolumn{4}{|l|}{ Histology $(N(\%))$} \\
\hline Fusiform & $19(59.3)$ & $3(42.8)$ & 1.000 \\
\hline Mixed morphology & $5(15.6)$ & $2(28.6)$ & \\
\hline Epithelioid & $8(25.0)$ & $2(28.6)$ & \\
\hline \multicolumn{4}{|l|}{ AFIP-Mettienen risk classification } \\
\hline High & $9(28.1)$ & $1(14.3)$ & 0.652 \\
\hline Intermediate & $2(6.2)$ & $1(14.3)$ & 0.457 \\
\hline Low & $8(25.1)$ & $2(28.6)$ & 1.000 \\
\hline Very low & $13(40.6)$ & $3(42.8)$ & 1.000 \\
\hline Preoperative imatinib therapy $(N(\%))$ & $3(9.3)$ & $1(14.3)$ & 0.562 \\
\hline Adjuvant imatinib therapy $(N(\%))$ & $12(37.5)$ & - & 0.077 \\
\hline \multicolumn{4}{|l|}{ Surgical margin status $(N(\%))$} \\
\hline $\mathrm{R} 0$ & $29(90.6)$ & $7(100)$ & 1.000 \\
\hline $\mathrm{R} 1$ & $3(9.4)$ & - & \\
\hline
\end{tabular}

including sarcomas, endocrine, head and neck malignancies, and rare tumors, accounted for a proportion ranging from 0.5 to $11.0 \%$.

Five-year survival rate was reported in the review by Núnez Martín et al., who found that $77.1 \%$ of patients with isolated GIST were alive after 5 years from surgery, whereas only $48.4 \%$ of patients with GIST and SPT were alive at 5year follow-up [23].

\section{Discussion}

Over the past 20 years, there have been major advances in the diagnosis and treatment of GISTs. Nonetheless, although knowledge on GISTs has made extraordinary progress, little is known about the concomitant appearance of other tumors, either synchronous or metachronous, in a non-negligible percentage of GIST patients.

In most cases, studies conducted on this topic are represented by case reports, while studies on larger samples and above all meta-analyses are limited and still insufficient to understand the pathogenesis of this phenomenon $[17,25,26]$.

In 2000, a study conducted on a small sample of patients by Maiorana et al. described for the first time the occurrence of other cancers in patients with GIST. The authors analyzed 52 cases of gastric GIST and found the presence of a second neoplasm in six cases, represented by a gastric adenocarcino$\mathrm{ma}$ in five cases and a carcinoid tumor in one case [27].

The frequency of synchronous or metachronous SPTs in patients with GIST, is widely variable among different studies published in the literature $[11,13,14,16]$. In the present study, a frequency of $17.9 \%$ has been detected, while our overview 
Fig. 1 Systematic review (SR) selection flowchart

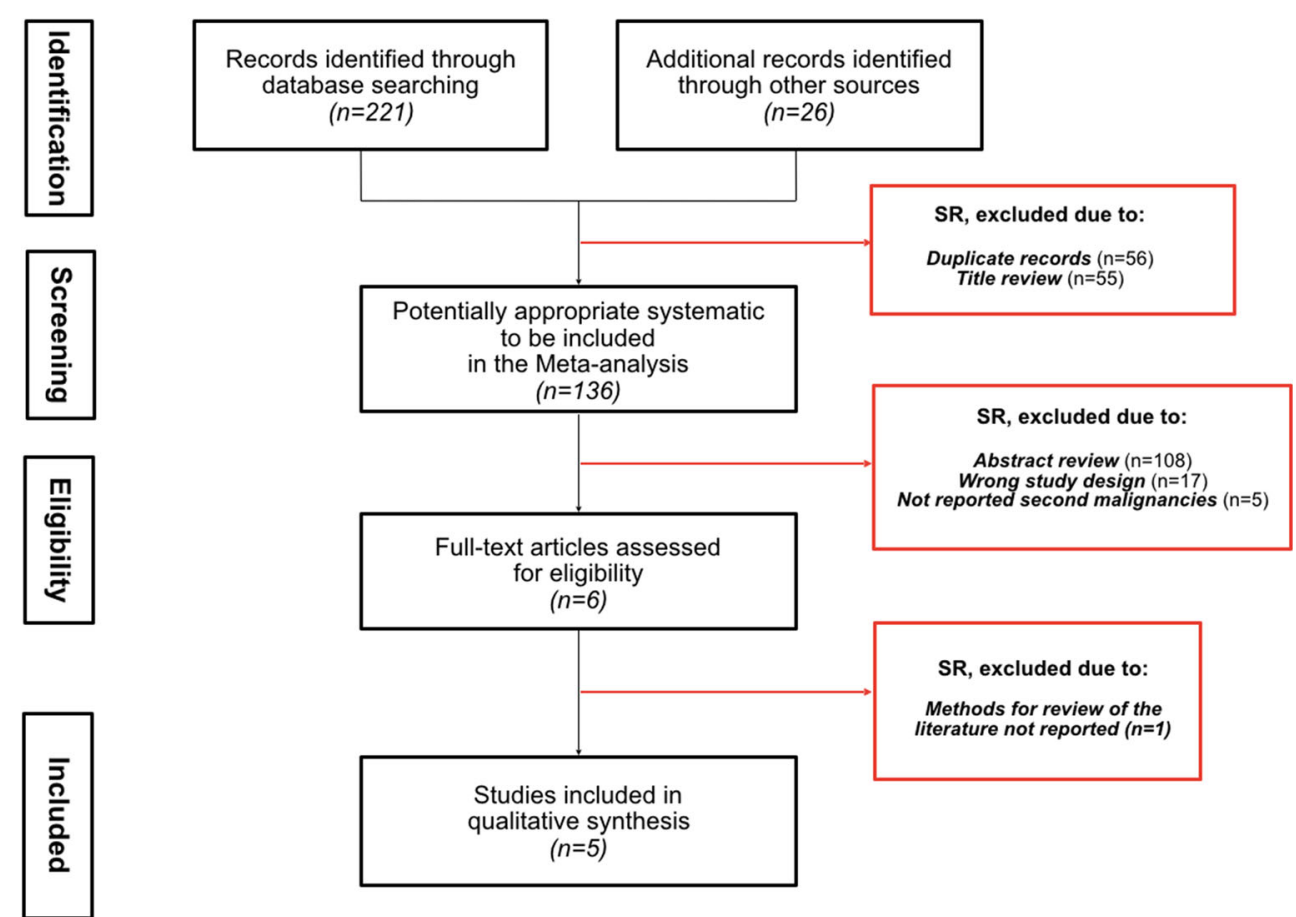

of systematic reviews shows that the cumulative prevalence rate of SPTs ranges from 9.3\% in the study by Agaimy et al. [7] to $18.0 \%$ in the study by Diamantis et al. [24], with a mean prevalence rate of $14.5 \%$. In comparison, surveillance, epidemiology, and end results data using an age-matched population shows that the overall risk of developing any type of cancer in the general population is approximately 10\% [28].

According to the findings of this study, the main anatomic sites of origin of GISTs with SPTs were the stomach in four patients $(57.1 \%)$, ileum in two cases $(28.6 \%)$, and two GISTs were diagnosed in the same patients in the stomach and small intestine in one case (14.3\%).

In the same way, the overview of systematic reviews demonstrated that the most frequent anatomic sites of origin of GISTs with SPTs were the gastroesophageal tract (62.7$67.2 \%$ ), followed by the small bowel (19.8-28.1\%) and the colorectal tract (2.8-3.6\%).

The majority of tumors found in association with GISTs are epithelial in nature $[13,18,25]$. The most reported types of GIST-associated malignancies are gastrointestinal carcinomas $(47 \%)$, carcinomas of the prostate $(9 \%)$, breast $(7 \%)$, kidney (6\%), lung (5\%), female genital tract (5\%), lymphoma/ leukaemia (7\%), carcinoid tumors (3\%), soft tissue and bone sarcomas $(3 \%)$, malignant melanoma (2\%), and seminoma (1\%) $[29,30]$.

Our results are in keeping with the existing literature, as two GIST patients were diagnosed with colorectal adenocarcinoma, one patient with laringeal adenocarcinoma, one patient with endometrial adenocarcinoma, and one with prostatic adenocarcinoma. Further two patients were diagnosed with
SPTs being osteosarcoma in one case and liposarcoma the second case.

In 2016, Fernández et al. proposed a classification based on the temporal association between GISTs and other malignancies, dividing the patients into four types according to two main factors: which tumor was the index one, and if the associated neoplasm was synchronic or metachronic [22]. In 2018, the same authors first reported a series of patients diagnosed with GISTs associated with other SPTs, comparing the different subgroups of associated GISTs according to the proposed classification. Main study findings showed that in $41.2 \%$ of patients the diagnosis of both GIST and SPT was synchronic. In $23.5 \%$ of cases, the associated tumors were diagnosed before GIST, in $35.2 \%$ of cases were diagnosed after GIST, and in $2.9 \%$ of cases SPTs were diagnosed as synchronous associated neoplasm during GIST staging [11].

In our study, the majority of GIST patients with associated tumors were diagnosed with a SPT during follow-up (10.2\% of the whole cohort). In three cases, the diagnosis of GIST was established during the associated epithelial tumor follow-up, whereas in one case, the diagnosis of GIST was carried out first, and the metachronous associated neoplasm was diagnosed during GIST follow-up.

These results are in contrast to the systematic review and meta-analysis published by Petrelli et al., which found that, among 16,892 GIST patients with data available for timing of SPTs, 14.6 and $7.9 \%$ had synchronous and metachronous SPTs, respectively [25].

Based on the data reported in the literature, the prognosis of patients with GIST associated with SPT appears to be worse 
Table 4 Overview of systematic reviews on GISTs associated with SPTs

\begin{tabular}{|c|c|c|c|c|c|}
\hline Author & Petrelli F. & Diamantis A. & Núnez-Martín R. & Giuliani J. & Agaimy A. \\
\hline Year & 2019 & 2018 & 2017 & 2015 & 2006 \\
\hline No. of included studies & 32 & 10 & 9 & 6 & 14 \\
\hline R-AMSTAR score & 36 & 24 & 22 & 22 & 24 \\
\hline No. of included patients & 18170 & 1108 & 9261 & 445 & 4777 \\
\hline GIST + SPT $(N(\%))$ & $2414(13.2)$ & $202(18.0)$ & $1602(17.3)$ & $64(14.5)$ & $444(9.3)$ \\
\hline Mean age (years) $\pm \mathrm{SD}$ & $63.2 \pm 3.6$ & 77 & NR & $67.0 \pm 2.1$ & NR \\
\hline Sex: male/female $(\%)$ & $\begin{array}{l}1266 / 1044 \\
(54.8 / 45.2)\end{array}$ & $647 / 461(58.4 / 41.6)$ & NR & NR & NR \\
\hline $\begin{array}{l}\text { Site of GIST with SPT } \\
\qquad(N(\%))\end{array}$ & $\begin{array}{l}\text { GE, } 717 \text { (67.2); SB, } \\
212 \text { (19.8); CR, } 30 \\
\text { (2.8); other, } 107 \\
\text { (9.9) }\end{array}$ & NR & NR & $\begin{array}{l}\text { GE, } 123(62.7) ; \mathrm{SB} \text {, } \\
55(28.1) ; \mathrm{CR}, 7 \\
\text { (3.6); other, } 11 \\
\text { (5.6) }\end{array}$ & NR \\
\hline $\begin{array}{l}\text { GIST with SPT mean size } \\
\quad(\mathrm{cm} \pm \mathrm{SD})\end{array}$ & $6.7 \pm 2.3$ & $17.8 \pm 8.1$ & NR & $3.9 \pm 0.7$ & NR \\
\hline $\begin{array}{l}\text { AFIP-Mettienen risk } \\
\text { category }(N(\%))\end{array}$ & $\begin{array}{l}\text { High, } 367(25.6) ; \text { Int, } \\
\quad 336(23.5) ; \\
\text { low/very low, } 688 \\
\text { (48.1); unknown, } \\
40(2.8)\end{array}$ & $\begin{array}{l}\text { High/Int, } 165(14.9) ; \\
\text { low/very low, } 943 \\
(85.1)\end{array}$ & NR & $\begin{array}{l}\text { High, } 26 \text { (13.2); Int, } \\
54 \text { (27.6); low, } 47 \\
\text { (24.0); very low, } \\
69(35.2)\end{array}$ & NR \\
\hline Site of SPT & $\begin{array}{l}\text { GI: } 923 \text { (37.9); GU, } \\
542 \text { (22.4); GYN, } \\
91(3.7) ; \text { THOR, } \\
134 \text { (6.2); breast, } \\
111(4.6) ; \text { skin, } 112 \\
\text { (4.6); CNS, } 13 \\
\text { (0.5); HEM, } 153 \\
\text { (6.3); other, } 231 \\
\text { (9.5); benign, } 29 \\
\text { (1.2); unknown, } 75 \\
\text { (3.1) }\end{array}$ & $\begin{array}{l}\text { GI, } 192(95.0) \text {; GU, } 5 \\
\text { (2.5); GYN, } 2 \\
\text { (1.0); THOR, -; } \\
\text { breast, -; skin, -; } \\
\text { CNS, -; HEM, } 2 \\
\text { (1.0); other, } 1(0.5) \text {; } \\
\text { benign, -; } \\
\text { unknown, - }\end{array}$ & GI and GU & $\begin{array}{l}\text { GI, } 130(67.3) ; \\
\text { GU,18 (9.2); } \\
\text { GYN, } 14(7.1) ; \\
\text { THOR, -; breast, } \\
18 \text { (9.2); skin, -; } \\
\text { CNS, -; HEM, } 7 \\
\text { (3.6); other, } 7 \\
\text { (3.6); benign, -; } \\
\text { unknown, - }\end{array}$ & $\begin{array}{l}\text { GI, } 247 \text { (55.6); GU, } 86 \\
\text { (19.3); GYN, } 25(5.6) ; \\
\text { THOR, } 26(5.8) \text {; } \\
\text { breast, } 34 \text { (7.6); skin, } \\
12(2.7) \text {; CNS, } 2 \text { (0.5); } \\
\text { HEM, } 36 \text { (8.1); other, } \\
39(11.0) \text {; benign, } 1 \\
\text { (0.2); unknown, - }\end{array}$ \\
\hline Synchronous/metachronous & $1060 / 369(74.2 / 25.8)$ & $202 / 0(100 / 0)$ & NR & NR & NR \\
\hline 5-year survival & NR & NR & $\begin{array}{l}\text { Isolated GISTs, } \\
\text { 77.1\% GIST + } \\
\text { other malignancies, } \\
48.4 \%\end{array}$ & NR & NR \\
\hline Conclusions & $\begin{array}{l}20 \% \text { of patients with } \\
\text { GIST experienced a } \\
\text { SPT, with } 14 \text { and } \\
3 \% \text { being } \\
\text { synchronous and } \\
\text { metachronous } \\
\text { tumors, } \\
\text { respectively. The } \\
\text { most frequently } \\
\text { associated SPTs } \\
\text { were colorectal } \\
(17 \%), \text { prostate } \\
(14 \%), \text { and gastric } \\
(9 \%) .\end{array}$ & $\begin{array}{l}\text { Synchronous } \\
\text { intra-abdominal } \\
\text { SPTs were found in } \\
18 \% \text { of all GISTs } \\
\text { patients studied. } \\
\text { The mean age was } \\
70.5 \text { years, affect- } \\
\text { ing more the male } \\
\text { gender }(65 \%) \text {. The } \\
\text { mean size of the } \\
\text { concurrent GISTs } \\
\text { was } 18 \text { mm while } \\
\text { the most common } \\
\text { GIST-associated } \\
\text { malignancy were } \\
\text { gastric adenocarci- } \\
\text { nomas. }\end{array}$ & $\begin{array}{l}\text { GIST patients have a } \\
\text { 2-fold risk of de- } \\
\text { veloping a SPT } \\
\text { than the general } \\
\text { population (4-33\% } \\
\text { of them develop a } \\
\text { second neoplasm, } \\
\text { either synchronic or } \\
\text { metachronic). Most } \\
\text { incident tumors as- } \\
\text { sociated with GIST } \\
\text { are gastrointestinal } \\
\text { and genitourinary } \\
\text { tumors. Patients } \\
\text { with SPT have a } \\
\text { worse survival rate } \\
\text { than those without } \\
\text { SPT. }\end{array}$ & $\begin{array}{l}\text { 14.5\% of patients } \\
\text { with GIST present } \\
\text { with other } \\
\text { synchronous SPT }\end{array}$ & $\begin{array}{l}\text { About } 10 \% \text { of all GISTs } \\
\text { develop in patients } \\
\text { with other cancer either } \\
\text { synchronously or } \\
\text { metachronously. } \\
\text { Potential nonrandom } \\
\text { association and causal } \\
\text { relationship between } \\
\text { these neoplasms } \\
\text { remains to be } \\
\text { investigated. Major } \\
\text { types of } \\
\text { GIST-associated can- } \\
\text { cers were GI carcino- } \\
\text { mas (47\%), carcinomas } \\
\text { of prostate (9\%), breast } \\
\text { (7\%), kidney (6\%), } \\
\text { lung (5\%), female gen- } \\
\text { ital tract (5\%), and } \\
\text { lymphoma/leukaemia } \\
\text { (7\%). }\end{array}$ \\
\hline
\end{tabular}

$G E$, gastro-esophageal; $S B$, small bowel; $C R$, colorectal; $G I$, gastro-intestinal; $G U$, genito-urinary; $G Y N$, gynecologic; $T H O R$, thoracic; $C N S$, central nervous system; $H E M$, hematologic; $N R$, not reported; $S P T$, second primary tumor 
than patients with isolated GISTs, and it appears to be influenced by GIST-associated neoplasms than by GISTs themselves. As reported in our overview, Núnez-Martín et al. found that 5-year survival in isolated GIST patients was almost doubled compared with patients having associated malignancies (77.1 vs. $48.4 \%)$ [23].

Vassos et al. followed up GIST patients with SPT for an average period of 66 months. At the end of this follow-up time, most of the patients with low risk GIST were still alive $(64.5 \%)$, whereas $19.5 \%$ died of recurrence or metastatic disease from SPT. No patient died due to GIST. Furthermore, in the cases of intermediate risk GIST, after a mean follow-up of 40 months, most of the patients were still alive (66.7\%) [31].

Similarly, Kramer et al. followed-up 267 GIST patients and associated other neoplasms for an average period of 4 years. The authors reported 19 GIST-related deaths and 98 due to other causes. Overall survival at 1,3, and 5 years was 88.5, 75, and $62.8 \%$, respectively, while specific disease survival was 99, 96.5, and 90.8\%. In patients with isolated GIST, instead, the overall survival at 1,3 , and 5 years was 94, 88.3, and $83.4 \%$, respectively, whereas the specific disease survival was 96.6, 93.4, and 90.9\% [15].

Different aetiopathogenetic hypotheses have been suggested to explain the occurrence of synchronous or metachronous tumors in GIST patients, but the underlying pathogenic mechanisms have not yet been fully explained. One of the hypotheses is that there are carcinogens which, acting on neighboring tissues or involving common molecular pathways, lead to the proliferation of both epithelial and stromal cell lines [31-33].

Also iatrogenic causes have been taken into account to explain the correlation between GIST and other neoplasms. Kanda et al. observed that imatinib is able to induce genitourinary tract tumors in mice, so it has been hypothesized that the treatment of GIST with tirosine kinase inhibitors may be responsible for the onset of renal cell carcinoma in patients with a previous history of GIST [34].

However, although the study by Mendonca et al. suggested a possible association of renal cell carcinoma with GISTs, there is no experimental evidence supporting the role of imatinib in the carcinogenesis of solid tumors, and the rarity of renal cell carcinomas arising in patients with chronic myeloid leukemia treated with this drug, argues against this hypothesis.

In view of the high incidence of gastric GISTs associated with gastric cancer, also Helicobacter Pylori (HP) infection has been assessed as a possible risk factor [12, 27, 33]. Currently the only neoplasms where an association with HP has been demonstrated are gastric adenocarcinoma and gastric MALT, but it has been hypothesized that this bacterium may be involved in the carcinogenesis of other tumors. Recent case reports have shown the association of GISTs with gastric carcinomas and gastric MALT in HP positive patients. This finding, together with the frequent gastric localization of GISTs, has led to the hypothesis that HP may play a role in GIST carcinogenesis and that it may be involved in some tumor associations, in particular between GIST and gastric carcinomas [35]. However, given the contrast between the high incidence of HP infection in the global population and the rarity of GISTs, the presence of HP in some cases of GIST associated with other neoplasms could be an absolutely random effect.

Finally, apart from the various hypotheses proposed to explain the occurrence of synchronous or metachronous tumors in GIST patients, this association could also be purely coincidental.

In support of this argument, there is the fact that in many studies, including the present, the average age of GIST patients associated with SPT at the time of diagnosis was found to be greater than that found in patients with GIST alone (56.8 \pm 15.2 vs. $73.4 \pm 16.6$ ), whereas other variables, such as GIST size, mitotic index, Ki-67 expression, and AFIP risk classification score were comparable between the two groups of patients.

This result is probably due to the fact that with increasing age the risk of developing other neoplasms increases in parallel, due to phenomena of ageing, such as the alteration of gene expression and weakening of the immune system [30, 31].

Data reported in the literature do not seem to show any link between the site of onset of GISTs and the appearance of synchronous or metachronous tumors [12, 15, 32, 33]. However, according to what we have found in our study, GISTs associated with SPTs are generally smaller than isolated ones (although the difference was not statistically significant), and this could be due to the fact that they are diagnosed early thanks to the symptoms related to the associated neoplasms or to the diagnostic and therapeutic procedures performed for the latter.

Possible limitations of this study are related to its retrospective, non-randomized design, which carries a high risk of selection bias. The single-institutional nature of the study, and the relatively small sample size could also affect the generalizability of the results. Therefore, the level of evidence behind the results of the present study is not high. With regard to the overview of systematic reviews, main limitations are related to the fact that this was not an individual patient data analysis, and therefore the characteristics of GIST patients developing SPTs were not known.

Furthermore, it is difficult to properly assess the relationship between GISTs and SPTs since, having been only recently defined the diagnostic criteria of GISTs, these tumors are often not considered in the elaboration of the statistics on cancer and consequently the epidemiological data on this topic may be extremely inaccurate. 


\section{Conclusions}

Our experience shows that GIST patients managed in the current institution experienced a $17.9 \%$ overall risk for both synchronous $(7.7 \%)$ and metachronous $(10.2 \%)$ tumors of different histology, and our overview of systematic reviews showed that the cumulative prevalence rate of SPTs ranges from 9.3 to $18.0 \%$. Notably, for currently unknown reasons, there seems to be an excess of second gastrointestinal and genitourinary epithelial tumors in GIST patients compared with the general population. This association should always be considered, and a thorough workup in patients presenting with gastrointestinal symptoms and a GIST diagnosis should be routinely performed in order to investigate the presence of a SPT.

Comparing patients with isolated GIST and patients with GIST and SPT, age was the only variable significantly related to the development of other neoplasms. However, the potential non-random association and causal relationship between GISTs and SPTs remains not clearly investigated. Indeed, although coincidence in itself may be the answer, the hypotheses of gene mutation or the same carcinogenic agent resulting in two tumors of different origin cannot be excluded.

Author Contribution Mauro Podda: Study conception and design, literature search, acquisition, interpretation, and analysis of data; drafting and critically revising the article for important intellectual content; and final approval of the version to be published. Giulia Ferraro: Study conception and design, literature search, acquisition, interpretation, and analysis of data; drafting and critically revising the article for important intellectual content; and final approval of the version to be published. Salomone Di Saverio: Interpretation and analysis of data; drafting and critically revising the article for important intellectual content; and final approval of the version to be published. Alessandro Cois: Interpretation and analysis of data; critically revising the article for important intellectual content; and final approval of the version to be published. Oreste Nardello: Interpretation and analysis of data; critically revising the article for important intellectual content; and final approval of the version to be published. Gaetano Poillucci: Interpretation and analysis of data; critically revising the article for important intellectual content; and final approval of the version to be published. Marco Vito Marino: Interpretation and analysis of data; critically revising the article for important intellectual content; and final approval of the version to be published. Adolfo Pisanu: Study conception and design, literature search, interpretation and analysis of data; drafting and critically revising the article for important intellectual content; and final approval of the version to be published.

Funding information This research did not receive any specific grant from funding agencies in the public, commercial, or not-for-profit sectors

\section{Compliance with Ethical Standards}

Conflicts of Interest The authors declare that they have no conflict of interest.

Ethical Approval All procedures performed in this study were in accordance with the ethical standards of the 1964 Helsinki declaration and its later amendments or comparable ethical standards. This study was conducted after the approval of the Institutional Ethics Review Board of the Azienda Ospedaliero-Universitaria di Cagliari, Cagliari University Hospital "D. Casula," Cagliari, Italy.

Informed Consent An informed consent for enabling the sharing of research data was obtained from all individual patients included in the study.

\section{References}

1. Mazzola P, Spitale A, Banfi S, Mazzucchelli L, Frattini M, Bordoni A. Epidemiology and molecular biology of gastrointestinal stromal tumors (GISTs): a population-based study in the South of Switzerland, 1999-2005. Histol Histopathol. 2008;23:1379-86. https://doi.org/10.14670/HH-23.1379.

2. Miettinen M, Lasota J, Sobin LH. Gastrointestinal stromal tumors of the stomach in children and young adults: a clinicopathologic, immunohistochemical, and molecular genetic study of 44 cases with long-term follow-up and review of the literature. Am J Surg Pathol. 2005;29:1373-81. https://doi.org/10.1097/01.pas. $0000172190.79552 .8 b$.

3. Søreide K, Sandvik OM, Søreide JA, Giljaca V, Jureckova A, Bulusu VR. Global epidemiology of gastrointestinal stromal tumours (GIST): a systematic review of population-based cohort studies. Cancer Epidemiol. 2016;40:39-46. https://doi.org/10. 1016/j.canep.2015.10.031

4. Miettinen M, Lasota J. Gastrointestinal stromal tumors - definition, clinical, histological, immunohistochemical, and molecular genetic features and differential diagnosis. Virchows Arch. 2001;438:1-12. https://doi.org/10.1007/s004280000338.

5. Miettinen M, Majidi M, Lasota J. Pathology and diagnostic criteria of gastrointestinal stromal tumors (GISTs): a review. Eur J Cancer. 2002;38(Suppl 5):S39-51. https://doi.org/10.1016/S09598049(02)80602-5.

6. Tran T, Davila JA, El-Serag HB. The epidemiology of malignant gastrointestinal stromal tumors: an analysis of 1,458 cases from 1992 to 2000. Am J Gastroenterol. 2005;100:162-8. https://doi. org/10.1111/j.1572-0241.2005.40709.x.

7. Agaimy A, Wünsch PH, Sobin LH, Lasota J, Miettinen M. Occurrence of other malignancies in patients with gastrointestinal stromal tumors. Semin Diagn Pathol. 2006;23:120-9. https://doi. org/10.1053/j.semdp.2006.09.004.

8. Machado-Aranda D, Malamet M, Chang YJ, Jacobs MJ, Ferguson L, Silapaswan S, et al. Prevalence and management of gastrointestinal stromal tumors. Am Surg. 2009;75:55-60.

9. Dematteo RP, Gold JS, Saran L, Gönen M, Liau KH, Maki RG, et al. Tumor mitotic rate, size, and location independently predict recurrence after resection of primary gastrointestinal stromal tumor (GIST). Cancer. 2008;112:608-15. https://doi.org/10.1002/cncr. 23199.

10. Nilsson B, Bümming P, Meis-Kindblom JM, Odén A, Dortok A, Gustavsson B, et al. Gastrointestinal stromal tumors: the incidence, prevalence, clinical course, and prognostication in the preimatinib mesylate era-a population-based study in western Sweden. Cancer. 2005;103:821-9. https://doi.org/10.1002/cncr.20862.

11. Fernández JA, Olivares V, Gómez-Ruiz AJ, Ferri B, Frutos MD, Soria $\mathrm{T}$, et al. Additional malignancies in patients with gastrointestinal stromal tumors (GIST): incidence, pathology and prognosis according to a time of occurrence-based classification. Clin Transl Oncol. 2019;21:646-55. https://doi.org/10.1007/s12094-018-1966-5.

12. Liszka Ł, Zielińska-Pajak E, Pajak J, Gołka D, Huszno J. Coexistence of gastrointestinal stromal tumors with other 
neoplasms. J Gastroenterol. 2007;42:641-9. https://doi.org/10. 1007/s00535-007-2082-4.

13. Gonçalves R, Linhares E, Albagli R, Valadão M, Vilhena B, Romano S, et al. Occurrence of other tumors in patients with GIST. Surg Oncol. 2010;19:e140-3. https://doi.org/10.1016/j. suronc.2010.06.004.

14. Mendonca SJ, Sanchez A, Blum KA, Ghanaat M, Kashan MY, Benfante $\mathrm{N}$, et al. The association of renal cell carcinoma with gastrointestinal stromal tumors. J Surg Oncol. 2018;117:1716-20. https://doi.org/10.1002/jso.25080.

15. Kramer K, Wolf S, Mayer B, Schmidt SA, Agaimy A, Henne-Bruns $\mathrm{D}$, et al. Frequence, spectrum and prognostic impact of additional malignancies in patients with gastrointestinal stromal tumors. Neoplasia. 2015;17:134-40. https://doi.org/10.1016/j.neo.2014. 12.001 .

16. Du J, Shen N, He HS, Fu XL, Wang JZ, Mao CZ. Synchronous gastrointestinal cancer and gastrointestinal stromal tumors: a singleinstitution experience. World J Surg Oncol. 2016;14:130. https:// doi.org/10.1186/s12957-016-0882-9.

17. Giuliani J, Bonetti A. The occurrence of gastrointestinal stromal tumors and second malignancies. J Gastrointest Cancer. 2015;46: 408-12. https://doi.org/10.1007/s12029-015-9759-3.

18. Hechtman JF, DeMatteo R, Nafa K, Chi P, Arcila ME, Dogan S, et al. Additional primary malignancies in patients with gastrointestinal stromal tumor (GIST): a clinicopathologic study of 260 patients with molecular analysis and review of the literature. Ann Surg Oncol. 2015;22:2633-9. https://doi.org/10.1245/s10434-014-4332-z.

19. Catena F, Di Battista M, Ansaloni L, Pantaleo M, Fusaroli P, Di Scioscio V, et al. Microscopic margins of resection influence primary gastrointestinal stromal tumor survival. Onkologie. 2012;35: 645-8. https://doi.org/10.1159/000343585.

20. Miettinen M, Lasota J. Gastrointestinal stromal tumors: pathology and prognosis at different sites. Semin Diagn Pathol. 2006;23(2): 70-83. https://doi.org/10.1053/j.semdp.2006.09.001.

21. Kung J, Chiappelli F, Cajulis OO, Avezova R, Kossan G, Chew L, et al. From systematic reviews to clinical recommendations for evidence-based health care: validation of revised assessment of multiple systematic reviews (R-AMSTAR) for grading of clinical relevance. Open Dent J. 2010;4:84-91. https://doi.org/10.2174/ 1874210601004020084

22. Fernández Hernández JÁ, Olivares Ripoll V, Parrilla Paricio P. Asociación de tumores del estroma gastrointestinal con otros tumores primarios. Propuesta de una nueva clasificación. Med Clín. 2016;147:405-9. https://doi.org/10.1016/j.medcli.2016.06. 006.

23. Núñez-Martín R, Cubedo Cervera R, Provencio Pulla M. Gastrointestinal stromal tumour and second tumours: a literature review. Med Clin (Barc). 2017;149:345-50. https://doi.org/10. 1016/j.medcli.2017.06.010

24. Diamantis A, Bouliaris K, Christodoulidis G, Vasdeki D, Perivoliotis K, Tepetes K. Gastrointestinal stromal tumors and synchronous intra-abdominal malignancies: review of the literature. $\mathrm{J}$ BUON. 2018;23:1573-9.
25. Petrelli F, Tomasello G, Barni S, Varricchio A, Costanzo A, Rampulla V, et al. Risk of second primary tumors in GIST survivors: a systematic review and meta-analysis. Surg Oncol. 2019;29: 64-70. https://doi.org/10.1016/j.suronc.2019.03.001.

26. Giuliani J, Marzola M, Indelli M, Aliberti C, Sartori S, Lanza G, et al. Gastrointestinal stromal tumors and other malignancies: a case series. J Gastrointest Cancer. 2012;43:634-7. https://doi.org/10. 1007/s12029-012-9371-8.

27. Maiorana A, Fante R, Maria Cesinaro A, Adriana Fano R. Synchronous occurrence of epithelial and stromal tumors in the stomach: a report of 6 cases. Arch Pathol Lab Med. 2000;124: 682-6. https://doi.org/10.1043/0003-9985(2000)124\%3C0682: SOOEAS\%3E2.0.CO;2.

28. The US National Cancer Institute's Surveillance Epidemiology and End Results (SEER) Database. https://seer.cancer.gov. Online Accessed 14 Aug 2019.

29. Wronski M, Ziarkiewicz-Wroblewska B, Gornicka B, Cebulski W, Slodkowski M, Wasiutynski A, et al. Synchronous occurrence of gastrointestinal stromal tumors and other primary gastrointestinal neoplasms. World J Gastroenterol. 2006;12:5360-2. https://doi.org/ 10.3748/wjg.v12.i33.5360.

30. Lin M, Lin JX, Huang CM, Zheng CH, Li P, Xie JW, et al. Prognostic analysis of gastric gastrointestinal stromal tumor with synchronous gastric cancer. World J Surg Oncol. 2014;12:25. https://doi.org/10.1186/1477-7819-12-25.

31. Vassos N, Agaimy A, Hohenberger W, Croner RS. Coexistence of gastrointestinal stromal tumours (GIST) and malignant neoplasms of different origin: prognostic implications. Int J Surg. 2014;12: 371-7. https://doi.org/10.1016/j.ijsu.2014.03.004.

32. Ferreira SS, Werutsky G, Toneto MG, Alves JM, Piantá CD, Breunig RC, et al. Synchronous gastrointestinal stromal tumors (GIST) and other primary cancers: case series of a single institution experience. Int J Surg. 2010;8:314-7. https://doi.org/10.1016/j.ijsu. 2010.03.008

33. Ponti G, Luppi G, Martorana D, Rossi G, Losi L, Bertolini F, et al. Gastrointestinal stromal tumor and other primary metachronous or synchronous neoplasms as a suspicion criterion for syndromic setting. Oncol Rep. 2010;23:437-44. https://doi.org/10.3892/or 00000653.

34. Kanda T. Criminal or bystander: imatinib and second primary malignancy in GIST patients. Chin J Cancer Res. 2013;25:490-2. https://doi.org/10.3978/j.issn.1000-9604.2013.10.15.

35. Kaffes A, Hughes L, Hollinshead J, Katelaris P. Synchronous primary adenocarcinoma, mucosa-associated lymphoid tissue lymphoma and a stromal tumor in a Helicobacter pylori-infected stomach. J Gastroenterol Hepatol. 2002;17:1033-6. https://doi.org/10. 1046/j.1440-1746.2002.02649.x.

Publisher's Note Springer Nature remains neutral with regard to jurisdictional claims in published maps and institutional affiliations. 